Arch. Dis. Childh., 1968, 43, 257.

\title{
Management of the Nephrotic Syndrome
}

\author{
GAVIN C. ARNEIL \\ From the Department of Child Health, University of Glasgow
}

The nephrotic syndrome may be defined as gross proteinuria, predominantly albuminuria, with consequent selective hypoproteinaemia; usually accompanied by oedema, ascites, and hyperlipaemia, and sometimes by systemic hypertension, azotaemia, or excessive erythrocyturia.

\section{Grouping of Nephrotic Syndrome}

The syndrome falls into three groups.

(1) Congenital nephrosis. A group of disorders present at and presenting soon after birth, which are familial and may be acquired or inherited. Persistent oedema attracts attention in the first weeks of life. The disease may be rapidly lethal, but occasionally the patient will survive for a year or more without fatal infection or lethal azotaemia. The disease pattern tends to run true within a family. It does not respond to steroid treatment, and palliation alone is possible. Death from infection is usual before renal failure proves lethal. This group has been well described by Hallman, Hjelt, and Ahvenainen (1956) and Lange et al. (1963), and will not be considered further.

(2) Secondary nephrosis. In this group of conditions a known primary disorder precedes or coexists with the nephrotic syndrome. Causes may be summarized as follows.

(a) Collagen disease: e.g. anaphylactoid purpura, disseminated lupus erythematosus, polyarteritis nodosa.

(b) Quartan malaria: as described from Nigeria (Gilles and Hendrickse, 1963).

(c) Post-nephritic state: a rare form following acute haemorrhagic glomerulonephritis.

(d) Heavy metal poisoning: due to lead or mercury.

(e) Renal vein thrombosis.

(f) Diverse rare causes: amyloidosis, diabetic glomerulosclerosis, neoplastic infiltration, snake bite, and many others.

\footnotetext{
* In the 'Personal Practice' series of articles an author is invited to set out his personal views on the handling of some current paediatric problem.
}

(3) Idiopathic nephrosis. This may be regarded either as a primary disease, or as a secondary disorder, with the primary cause or causes still unknown. It is the common form of nephrosis in childhood, but the less common in adult patients. Unless otherwise specified, the present discussion concerns idiopathic nephrosis.

\section{Assessment of the Case}

Full history and examination helps to exclude many secondary forms of the disease. Blood pressure is recorded employing as broad a cuff as practicable, and the width of the cuff used is recorded as of importance in comparative estimations. A careful search for concomitant infection is made, particularly to exclude pneumococcal peritonitis or low grade cellulitis. In a patient previously treated elsewhere, evidence of steroid therapy such as Cushingoid obesity, hirsutism, or striae is sought, and osteoporosis is then assessed radiologically. Oliguria is the rule in the oedematous phase, with marked hyposaluria (sodium excretion may be less than $1 \mathrm{mEq}$ daily). Urine osmolality and specific gravity should be within normal limits. Haematuria, when present, consists of intact erythrocytes rather than the smoky quality produced by lysis in the urine of acute haemorrhagic nephritis (Heymann et al., 1958).

The amount of protein in the urine fluctuates widely from patient to patient and from day to day in the same patient, and though arbitrary limits are of little practical use, an attempt must be made to define quantity per unit volume of urine, per unit time, or even per unit surface area in relation to unit time. Proteinuria usually exceeds $50 \mathrm{mg}$./hour and $1 \mathrm{~g}$./litre at onset. The Esbach test is used for rough quantitation, but the turbidimetric salicylsulphonic method is simple and useful for quantitation. The precise but laborious biuret method is not here employed for this measurement.

Microscopy of the urine gives diverse results. Casts vary in frequency and cellularity. White blood cells are rarely present in excess, save on the not rare occasions when pyuria is superimposed on 
the nephrotic syndrome. Red blood cells are present to gross excess in $10 \%$ of children and to microscopical excess in a further $15 \%$. Techniques of measuring haematuria vary, but our practice is to use quantitation per unit volume, employing a simple method such as that of McGeachie and Kennedy (1963) or Stansfeld and Webb (1953). The latter test is simpler and is recommended. These simple quantitations may be complicated by expression in terms of unit time and/or surface area as desired. Initial haematuria carries a bad prognosis, and in a recent series the mortality after 5-10 years was $17 \%$ and continuing illness $29 \%$ when there was initial haematuria, compared with $7 \%$ and $18 \%$, respectively, when there was not (Arneil and Lam, 1966).

Renal function tests. These are of limited value and this particularly applies to urea-clearance tests. The urea concentration and the endogenous creatinine-clearance tests are usually normal. Selectivity of proteinuria, if the estimation is available, is probably the most useful test of renal function applicable to this situation.

Renal biopsy. Percutaneous renal biopsy of the child is easy to essay but difficult to apply wisely or with consistent success. Such acupuncture is carried out by a trained person where there is certainty that two kidneys exist, and where there is no gross hypertension, hydronephrosis, or bleeding diathesis. With local anaesthesia it is technically easier, and probably more often successful than with general anaesthesia, which is nevertheless less traumatic physically and psychologically. Local anaesthesia for older children and general anaesthesia for younger children is probably a reasonable compromise. Of several simple marker techniques available, we prefer to take a straight posteroanterior film of the prone patient with a marker fixed on the skin at the proposed site of puncture; intravenous urography is then performed to check the correct placing of the marker, which is left in situ until the actual operation.

The necessarily limited amount of material provided often reduces the value of needle biopsy, so that there is something to be said for the view that if biopsy is vital for the patient a small open biopsy is justified. A good surgical biopsy is probably no more hazardous and is more informative than unskilled percutaneous needle biopsy. Although some specimens are disappointing in glomerular yield (i.e. less than 10 glomeruli), the practicability of repeated percutaneous biopsies in the same patient has made possible the serial study of individual diseased kidneys; this is a great advantage. The success rate of the procedure in our unit is about $85 \%$.

Electron microscopy, though yielding fascinating data on the pedicels of the epithelial cells, has so far contributed little to the practical management of the disease. Simple light microscopy of serial sections, cut at 2-4 $\mu$, yields valuable data if a range of stains (H. and E., P.A.S., silver, etc.) are employed to reveal the underlying tissue changes. Study of tubules, vessels, and interstitial tissue is of interest, but it is the glomeruli that yield the crucial data. A simple classification is:

(a) Light microscopy negative: no significant detectable lesion.

(b) Light microscopy positive: (i) Membranous: showing significant thickening of basement membrane; (ii) Proliferative: proliferative changes with or without membranous change.

(More detailed classifications demand an expert renal pathologist, and if unanimity of opinion is sought only one should be consulted!)

A further sophistication is the application of immunofluorescent techniques. The presence or absence of 'bumps' of immunoglobulin is established with specific antisera, whose delightful shimmer on microscopy beckons like will-o'-thewisp, and deludes the unwary employer of insufficiently specific agents just as successfully. The work of Drummond et al. (1966) in this respect is worthy of study.

Study of immune protein levels in serum. Investigation of various fractions such as complement and $\beta_{-\mathrm{I}-\mathrm{C}}-\mathrm{globulin}$ are now well established, but confined to a few centres. $\beta_{-1-c-g l o b u l i n}(a$ component of complement) is low in level in the plasma when complement is being used, and indicates immunological activity (West, Northway, and Davis, 1964; Gotoff et al., 1965). These techniques are of little help in idiopathic nephrosis. The simple plate tests for IgG are a much more practical proposition, but not yet of proven use.

Selectivity of proteinuria. Various techniques have been used to differentiate cases where small protein molecules mainly constitute the proteinuria from those where larger molecules also leak through the glomerular membrane. Immunological techniques for quantitative assay of the various components of protein in plasma and urine, and comparison of the relative proportions of each leaking out, have been developed by Blainey $e t$ al. (1960), Soothill (1962), Cameron and White (1965), and Cameron and Blandford (1966). Here, 
Cameron's method is used, the immunological tests being available as a 'prefabricated kit' readily used in any laboratory. Cameron found that the patient with a highly selective small-molecular leak tended to retain this pattern throughout the course of the illness, responded well to steroid, and had an excellent prognosis. Cases in which a greater proportion of larger protein molecules penetrated to the urine along with the albumin and small molecular $\gamma$-globulins had a much less good prognosis; the selectivity of proteinuria again remained constant throughout the illness. This simple test (which is mercifully independent of renal biopsy) seems the one most likely to predict the cases where steroid treatment will succeed, and those in which steroid resistance, poor response, or frequent relapse may be expected. Such data in the future may spare the patient excessive and useless steroid therapy in high dosage, and indicate the need for cytostatic and low dosage steroid therapy. Many clinicians may prefer to reserve biopsy for those whose protein clearance is not highly selective, unless a scientific trial is in progress.

\section{Treatment}

This is best considered under the headings of dietetic, antibiotic, diuretic, steroid, cytostatic, and terminal.

Dietetic. In the oedematous phase sodium intake is restricted to $0 \cdot 5-2 \mathrm{~g}$. daily, with a fluid intake of 0.5-1 litre. Such restriction rarely provokes diuresis, since the urinary sodium excretion may be as low as $1 \mathrm{mEq} /$ day, but it does help to slow the rate of oedema formation. A generous intake of protein is indicated to help minimize the katabolic loss (unless the level of blood urea be raised). Calorie restriction, with a high-protein content in the diet, accompanies intensive steroid therapy in an effort to reduce the development of Cushingoid obesity, moon face, and permanent cutaneous striae. A high-protein diet is continued as long as proteinuria with or without oedema persists, and until the onset of renal failure.

Dietetic treatment of chronic renal failure is beset with problems of personality. There was much to be said for allowing the patient free choice and little restriction when therapeutic nihilism was the rule. It behoves one to remember that to the child (who is about to die) food is a great comfort, and such essentials as mince, bread, and sausages probably justify their protein content on humanitarian grounds. All forms of dietetic restriction-alkaline ash diet, rice diet, Giovanetti diet-are but palliative, and may be an unwarranted imposition unless some positive action such as renal transplant is being considered in the future.

Antibiotic therapy. It is not our practice to give prophylactic antibiotic treatment when a patient is adequately supervised, though the use of cytostatic treatment may alter this practice in the future. Long-term use of antibiotics does not eliminate the hazard of infection by an organism resistant to the specific antibiotic employed. Immediate intensive antibiotic therapy is mandatory if infection arises. Pyelonephritis excluded, the antibiotic of choice in pyrexia of unknown origin, or infection, is penicillin. The reduction in the mortality of idiopathic nephrosis is certainly as much due to efficient antibiotics as to specific effect of steroid therapy.

Care is taken not to overlook concomitant bacterial pyelonephritis, which is by no means rare, and should be treated vigorously for not less than six months.

Diuretic therapy. Impressive diuresis is provoked by steroid therapy in over $90 \%$ of children with primary nephrosis. This, together with memories of the inefficacy of the older diuretic agents, such as plasma expanders and mercurials, has tended to obscure the usefulness of more modern diuretics. Steroid is the best form of diuretic for most cases, but other diuretics must be considered in the following circumstances.

Infection. When infection such as peritonitis, cellulitis, pneumonia, or pyelonephritis coexists with nephrotic oedema, steroid therapy may be better delayed until the infection is cleared.

Steroid 'resistance'. This is only accepted here after adequate steroid therapy has failed. Elsewhere, the demonstration of proliferative nephritis on renal biopsy may be accepted as proof of unsuitability for treatment. We do not consider the presence of non-selective proteinuria, or of azotaemia, systemic hypertension, or gross haematuria as absolute but rather as relative contraindications to the use of steroid therapy.

Steroid toxicity. Acute hypertension, severe seizures, osteoporosis with potential vertebral collapse, and papilloedema, in relation to previous steroid therapy, are contraindications. Diabetes mellitus, gross cutaneous striation, and severe dwarfing are also usually considered contraindications.

Percutaneous renal biopsy. If histology is essential before steroid therapy is begun, this is easier to carry out on a patient who has been rendered free of gross oedema and ascites. 
Miscellaneous. Periods such as that following exposure to chicken-pox are not considered a suitable time to begin intensive steroid therapy, and palliative diuretic treatment complements the use of $\gamma$-globulin.

Diuretic treatment is employed in association with a sodium-restricted diet (20-80 mEq daily) and possibly water restriction to $1 \mathrm{l}$. daily. It involves three drugs, (i) chlorothiazide: the dosage initially is 1-2 g. daily depending on the size of the child. If this fails, dosage is increased to $2-4 \mathrm{~g}$. daily, irrespective of the size of the patient. If this fails then, (ii) spironolactone $-A$ is added, $100 \mathrm{mg}$. daily in divided doses, together with, (iii) potassium supplements, best given as effervescent tablets of potassium bicarbonate, $0.5 \mathrm{~g}$. $(6.5 \mathrm{mEq}), 2$ to 4 tablets daily; alternatively potassium chloride may be given up to $4 \mathrm{~g}$./day (=54 mEq) but the entericcoated tablet must not be used.

There is no shortage of alternative diuretics, but while some (e.g. frusemide) may be as effective, none seems to produce a more reliable or safer diuresis or with less risk of hypokalaemia than the proven system outlined above.

\section{Steroid Treatment}

Short vs. prolonged steroid course. In 1950, when treatment with ACTH and cortisone first began, steroid treatment was given for a few days only and then stopped abruptly. Diuresis followed such short-term steroid on occasions, and 2 of our patients given $200 \mathrm{mg}$. cortisone daily for 5 days in 1952 promptly recovered and remain well 15 years later. Results improved considerably when intensive steroid therapy with prednisolone became available in 1955. Two principal methods of treatment evolved. The first consisted of an intensive course of treatment which was tailed off and then stopped, as shown in the Table (Arneil, 1956). The second consisted of intensive therapy

\section{TABLE}

Dosage of Steroid Therapy Employed (irrespective of size)

\section{Intensive Therapy}

$60 \mathrm{mg}$. prednisolone orally daily for 10 days $(15 \mathrm{mg} . \times 4)$ $40 \mathrm{mg}$. prednisolone orally daily for 10 days $(10 \mathrm{mg} . \times 4)$

$20 \mathrm{mg}$. prednisolone orally daily for 10 days $(5 \mathrm{mg} . \times 4)$

$10 \mathrm{mg}$. prednisolone orally for not less than 10 days $(5 \mathrm{mg} . \times 2)$, depending on absence of proteinuria.

\section{Intermittent Therapy}

20-40 mg. prednisolone orally daily for 3 consecutive days of each week, e.g. on Monday, Tuesday, and Wednesday, for minimum period of 3 months.

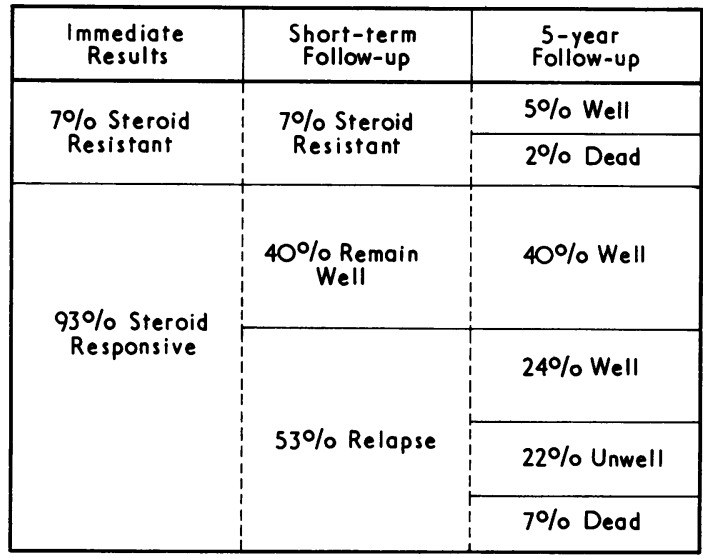

FIG. 1.-Immediate, short-term, and long-term results of intensive steroid therapy.

followed by some form of intermittent (e.g. three days every week) treatment over a period of years. The best known system of this type employed ACTH and cortisone (Lange, Wasserman, and Slobody, 1958); our own is shown in the Table. It is clear that any one of many different systems may be successful with a steroid-sensitive patient. Our own results with patients followed for a minimum of 5 years are shown in Fig. 1. Intensive steroid therapy has evoked diuresis in $93 \%$ of our 45 children with idiopathic nephrosis, with complete or considerable loss of proteinuria: $40 \%$ have not relapsed, $53 \%$ have relapsed, of whom $22 \%$ have recovered and $31 \%$ have remained unwell or have died (Arneil and Lam, 1966). These results should be interpreted against the results before steroid treatment, when $48 \%$ of children recovered, $20 \%$ died of infection within 2 years, and $18 \%$ died of renal failure within 10 years (Arneil, 1961).

When initial success has been achieved, the risk of giving prolonged intermittent therapy to the $40 \%$ of patients who would not relapse without it, must be balanced against the theoretical risk of increasing liability to one relapse by not giving intermittent therapy following the first response to steroid therapy. It is to be hoped that sophisticated techniques such as differential protein clearances, renal biopsy, immunoglobulin (Soothill, 1962),

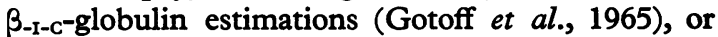
immunofluorescent techniques may prove helpful here. If they could indicate which patients were unlikely to relapse, one could avoid intermittent steroid prophylaxis for children who do not require it, and so avoid the Scylla of long-term unnecessary steroids for $40 \%$, and the Charybdis of delay in the start of long-term steroid treatment for the $53 \%$ 
who require it. It is our practice to give one intensive course, to stop, and, if relapse occurs, to give a second intensive course followed by intermittent treatment for a minimum of six months (Table).

The most vexatious problem arising from steroids relates not to the $40 \%$ who respond and recover, but to the $53 \%$ who, having responded in whole or in part, then relapse. A wide range exists, from the child who relapses once or twice in the first year after steroid treatment is begun, but not subsequent$l y$, to the child who relapses frequently with complete or incomplete clearance of proteinuria between successive episodes for five or more years. This group with recurrent relapses amounts to some $40 \%$ of all children with primary nephrosis. Some cases will have presented with initial haematuria, will have shown membranous and/or proliferative changes on light microscopy, and will have nonselective proteinuria, and it is amongst this group that the problems of prolonged steroid administration are most clamant.

Complications. These are similar to those seen in the natural disease of hypercorticism. The most common effect, Cushingoid obesity, may be reduced in part by the use of a high-protein and low-carbohydrate diet. Centripetal obesity, with buffalo hump and 'moon' or 'tomato' face, contributes to the stretching and striae of skin over certain areas such as the thighs, abdomen, and on occasions the pubescent mammae. The combination of obesity and oedema with underlying ascites may produce enough tension to cause rupture of striae with subcutaneous oedema leaking out and soaking the skin, a situation vulnerable to infection.

The second problem is that of osteoporosis. We record an osteoporotic index (relation of bicortical diameter to transverse diameter of three bones) initially, and every 3-6 months on steroid thereafter, depending on the intensity of steroid treatment. This gives some indication of the progression or otherwise of osteoporosis. Between intensive steroid courses or on intermittent therapy we encourage a high calcium (milk) intake and give supplements of vitamin $D$.

The third problem is that of stunting of growth. In any patient this is difficult to assess because of the variation in individual growth pattern, and the tendency to stunting in all chronic renal disease. It is to the latter group that the most steroid is likely to be given for the longest period.

It is because of this danger of growth retardation that various forms of intermittent therapy have been devised. Several theories have been advanced to justify the use of such intermittent therapy. It remains in doubt whether growth suppression is due to steroids competing with or suppressing production of pituitary growth hormone, or to the suppression of so-far unidentified growth-promoting substances in the adrenals.

It has been known for some time that a compensatory growth spurt often occurs after stopping a not too prolonged course of steroids (Blodgett et al., 1956); hence the observation of Friedman and Strang (1966), that oral steroids may cause more short-term growth retardation than ACTH intramuscularly, is less worrying.

Our own cases have recently been analysed, and indicate that intensive steroid therapy for up to 6 months has had no effect on height 5-12 years later. Dwarfism was found in those who had chronic renal disease of long duration and who had had many courses of steroid in high dosage, continuous low dosage, or intermittent dosage. Even in this group only some are seriously dwarfed, and a proportion of this stunting may be due to the renal disease, rather than to steroids.

Cytostatic (immunosuppressant) therapy. Several recent publications concern the use of drugs formerly called 'immunosuppressants', but not now thought to be so (White, Cameron, and Trounce, 1966; Shearn, 1965; Grupe and Heymann, 1966). The place for these drugs is obviously not in treating the $50 \%$ who recover within one year of onset on intensive steroid therapy alone, but (if anywhere) in the steroid-resistant, in the frequent relapser, and perhaps in those patients intolerant of high doses of steroid.

The theoretical reasons for the use of such cytotoxic agents as cyclophosphamide and azothioprine are tenuous, and there is at present no convincing trial of their efficiency. The best data are those of Michael et al. (1967) who showed that azothioprine had no worth-while effects on steroid-resistant idiopathic nephrotic syndrome, thus agreeing with Goodman et al. (1963), but not with Milliez, Lagrue, and Bariéty (1965). A large international trial of azothioprine plus steroid is under way.

Indications for considering cytostatic agents are: (a) unsatisfactory response to steroid courses; (b) proliferative glomerulonephritis on renal biopsy; (c) steroid toxicity in a responsive patient; (d) nonselective proteinuria; (e) anaphylactoid (SchönleinHenoch syndrome) glomerulonephritis persisting for more than 6 weeks.

A reasonable therapy would consist of azothioprine $2.5 \mathrm{mg} . / \mathrm{kg}$. per day, plus $10-20 \mathrm{mg}$. prednisolone daily for 60 days. If no response is 


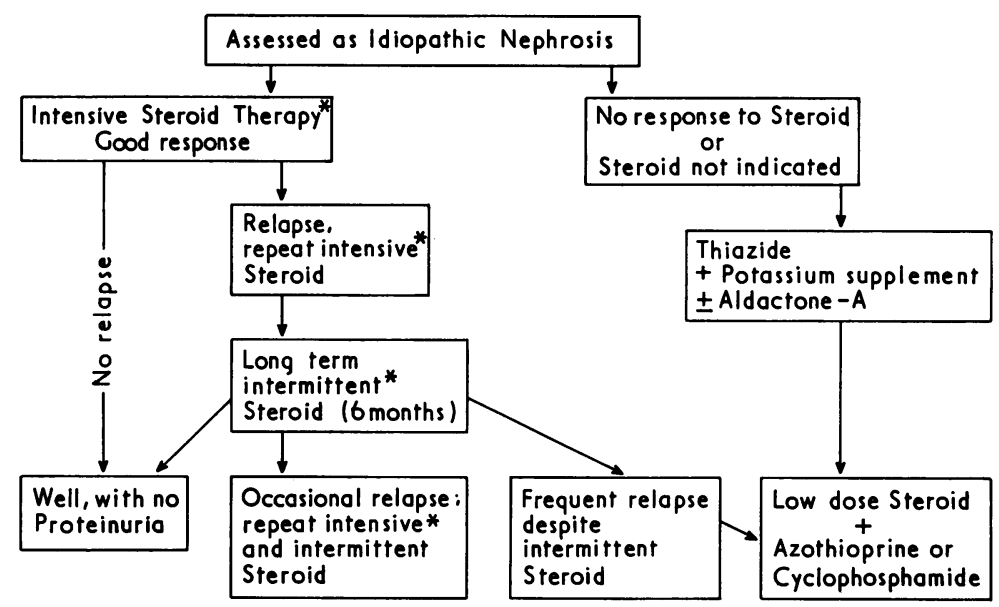

FIG. 2.-Proposed scheme for use of therapeutic agents in nephrosis. ${ }^{\star}$ For definition of intensive and intermittent steroid therapy, see Table.

obtained, treatment should probably then be discontinued. Throughout the period the white blood count and platelet count must be monitored several times weekly. Severe leucopenia and/or thrombocytopenia is an indication to discontinue azothioprine therapy and not to restart, since subsequent sensitivity is common.

Haemodialysis and renal transplant. In handling the hypertensive and chronic nephrotic in progressive renal failure, one must take stock of the probability of effective renal transplantation becoming available in the near future. Most paediatricians will feel that the physical, emotional, and economic complications of chronic haemodialysis do not justify the use of this technique in young children, unless leading up to renal transplant.

\section{Summary}

Fig. 2 summarizes the views set out in this article.

REFERENCES

Arneil, G. C. (1956). Treatment of nephrosis with prednisolone. Lancet, 1, 409.

- (1961). 164 children with nephrosis. ibid., 2, 1103.

- and Lam, C. N. (1966). Long-term assessment of steroid therapy in childhood nephrosis. ibid., $2,819$.

Blainey, J. D., Brewer, D. B., Hardwicke, J., and Soothill, J. F. (1960). The nephrotic syndrome. Diagnosis by renal biopsy and biochemical and immunological analyses related to the response to steroid therapy. Quart. F. Med., 29, 235.

Blodgett, F. M., Burgin, L., Iezzoni, D., Gribetz, D., and Talbot, N. B. (1956). Effects of prolonged cortisone therapy on the statural growth, skeletal maturation and metabolic status of children. New Engl. F. Med., 254, 636.

Cameron, J. S., and Blandford, G. (1966). The simple assessment of selectivity in heavy proteinuria. Lancet, 2, 242.

- and White, R. H. R. (1955). Selectivity of proteinuria in children with the nephrotic syndrome. ibid., 1, 463.

Drummond, K. N., Michael, A. F., Good, R. A., and Vernier, R. L. (1966). The nephrotic syndrome of childhood. $f$. clin. Invest., 45, 620 .
Friedman, M., and Strang, L. B. (1966). Effect of long-term corticosteroids and corticotrophin on the growth of children. Lancet, 2, 569.

Gilles, H. M., and Hendrickse, R. G. (1963). Nephrosis in Nigerian children. Role of plasmodium malariae, and effect of antimalarial treatment. Brit. med. $\mathcal{F}$., 2, 27.

Goodman, H. C., Wolff, S. M., Carpenter, R. R., Andersen, B. R., and Brandriss, M. W. (1963). Current studies on the effect of antimetabolites in nephrosis, other non-neoplastic diseases, and experimental animals. Ann. intern. Med., 59, 388.

Gotoff, S. P., Fellers, F. X., Vawter, G. F., Janeway, C. A., and Rosen, F. S. (1965). The $\beta$-r-c-globulin in childhood nephrotic syndrome. New Engl. F. Med., 273, 524.

Grupe, W. E., and Heymann, W. (1966). Cytotoxic drugs in steroid-resistant renal disease. Amer. F. Dis. Child., 112, 448.

Hallman, N., Hjelt, L., and Ahvenainen, E. K. (1956). Nephrotic syndrome in newborn and young infants. Ann. Paediat. Fenn., $2,227$.

Heymann, W., Rothenberg, M. B., Gilkey, C., and Lewis, M. (1958). Difference in color of hematuria in the nephrotic syndrome and glomerulonephritis. Pediatrics, 21, 375.

Lange, K., Wachstein, M., Wasserman, E., Alptekin, F., and Slobody, L. B. (1963). The congenital nephrotic syndrome. Amer. F. Dis. Child., 105, 338.

_, Wasserman, E., and Slobody, L. B. (1958). Prolonged intermittent steroid therapy for nephrosis in children and adults. F. Amer. med. Ass., 168, 377.

McGeachie, J., and Kennedy, A. C. (1963). Simplified quantitative method for bacteriuria and pyuria. F. clin. Path., 16, 32.

Michael, A. F., Vernier, R. L., Drummond, K. N., Levitt, J. I., Herdman, R. C., Fish, A. J., and Good, R. A. (1967). Immunosuppressive therapy of chronic renal disease. Nero Engl. $\mathcal{F}$. Med., 276, 817.

Milliez, P., Lagrue, G., and Bariéty, J. (1965). La chimiothérapie immunosuppressive des syndromes néphrotiques et de certaines glomérulonéphrites. Bull. Acad. nat. Méd. (Paris), 149, 259.

Shearn, M. A. (1965). Mercaptopurine in the treatment of steroidresistant nephrotic syndrome. New Engl. F. Med., 273, 943.

Soothill, J. F. (1962). Estimation of eight serum proteins by a gel diffusion precipitin technique. f. Lab. clin. Med., 59, 859.

Stansfeld, J. M., and Webb, J. K. G. (1953). Observations in pyuria in children. Arch. Dis. Childh., 28, 386.

West, C. D., Northway, J. D., and Davis, N. C. (1964). Serum levels of $\beta$-I-c-globulin, a complement component, in the nephritides, lipoid nephrosis, and other conditions. f. clin. Invest., 43, 1507.

White, R. H. R., Cameron, J. S., and Trounce, J. R. (1966). Immunosuppressive therapy in steroid-resistant proliferative glomerulonephritis accompanied by the nephrotic syndrome. Brit. med. F., 2, 853 . 